\title{
ENSINO FUNDAMENTAL DE NOVE ANOS: bases legais de sua implantação
}

\author{
Esméria de Lourdes Saveli*
}

\begin{abstract}
Resumo
O artigo discute a ampliação do Ensino Fundamental de oito para nove anos como uma política de inclusão social em que o Estado assume a garantia de acesso à escolaridade obrigatória e gratuita a todas as crianças na faixa etária de seis anos. Esta é uma política educacional de caráter afirmativo e sua efetivação, de fato, demanda pensá-la em seus aspectos políticos, administrativos e pedagógicos.

Palavras - chave: Política educacional. Ensino fundamental. Escolaridade obrigatória
\end{abstract}

\begin{abstract}
This paper discusses the extension of Primary Education from eight to nine years, as a policy of social inclusion in which the State guarantees access to free compulsory schooling for all children of six years of age. This educational policy has an affirmative character and its effective implementation demands consideration of political, administrative and pedagogical aspects.
\end{abstract}

Key words: Education policy. Elementary school. Compulsory school

\section{Introdução}

Este texto tem por objetivo discutir a ampliação do Ensino Fundamental de oito para nove anos como uma política afirmativa. Tal medida legal traz em seu bojo o princípio de inclusão onde os maiores beneficiados são as crianças oriundas das classes populares, pois as de classes mais privilegiadas já estão incluídas no sistema de escolarização obrigatório, há muito tempo.

É interessante que nós educadores, neste momento, de tanta polêmica sobre a inclusão das crianças de seis anos no sistema de escolaridade obrigatória, lancemos um olhar para a escola pública e tentemos desvendar quais os principais problemas que ela terá que enfrentar para acolher essas crianças no primeiro ano do ensino fundamental. O que leva as pessoas, inclusive educadores, a afirmarem que as crianças são muito "novinhas" para entrarem na escola? 0 que a inclusão das crianças de seis anos completos ou incompletos exige das escolas? A criança de seis anos completos ou a completar deixa de ser criança porque está incluída no Ensino Fundamental? O Ensino Fundamental não se constitui, enquanto etapa obrigatória da educação básica, como direito público subjetivo?

\section{A Educação como direito}

Sem desconsiderarmos que a Educação Infantil é a primeira etapa da educação básica, é necessário, também, discutirmos as questões levantadas no parágrafo anterior e outras tantas que têm polemizado sobre o recorte etário para as matrículas, a reorganização da Educação Infantil e dos anos iniciais do Ensino Fundamental. Reconhecemos a legitimidade das preocupações dos educadores, principalmente do campo da Educação Infantil, que têm tecido críticas veementes sobre a antecipação da escolaridade obrigatória. As críticas revelam uma preocupação com a escolarização considerada precoce das crianças de seis anos incompletos, razão pela qual, a discussão mais contundente gira em torno do corte etário. As controvérsias estão centradas em dois posicionamentos: os que são favoráveis à matrícula e à inclusão, no primeiro ano do Ensino Fundamental de nove anos, das crianças de seis anos completos ou a completar durante 0 ano letivo em curso, e aqueles que defendem o corte no mês de março, isto é, só poderão ser matriculadas, nesse primeiro ano, aquelas crianças que completarem seis anos até o início ou final de março em curso.

\footnotetext{
Professora do PPGE - UEPG. E-mail: esaveli@hotmail.com
} 
No entanto, em uma perspectiva comparada, verifica-se que, na maioria dos países, a escola obrigatória se inicia aos seis anos e, em muitos deles, aos cinco anos. A despeito das orientações emanadas do Conselho Nacional de Educação, há resistências em definir o corte etário de seis anos completos, para o ingresso da criança na escolarização formal.

Há um discurso de cunho ideológico de dirigentes educacionais, ligados às redes públicas municipais de ensino, de que a entrada precoce da criança no Ensino Fundamental poderá trazer prejuízos significativos para essas crianças, pois elas "são muito novinhas". No entanto, não há um movimento na mesma proporção para ampliar a oferta de classes de pré-escola para atender as crianças de cinco anos.

Essa política educacional implantada no Brasil a partir de 2006 se constitui em um instrumento legítimo para dar a todas as crianças, independente da classe social, a oportunidade de usufruir do direito de freqüentar mais cedo a escola. A justificativa de que são muito "novinhas" atinge mais as crianças oriundas das classes populares porque, conforme documento do MEC (2004), aquelas das classes mais privilegiadas já se encontram, em sua maioria, incluídas no sistema formal de ensino em classes de alfabetização, classes de pré-escola ou na primeira série do Ensino Fundamental. Entendemos que esse é um discurso de conteúdo ideológico que dá origem a preconceitos de valor social - "Ou, então, fundamenta posições jurídicas nítidas: tal grupo tem tais direitos próprios, que são conhecidos, na linguagem tradicional do Direito, como privilégios; outro não tem direitos, é um subgrupo, não pode se igualar aos demais" (COMPARATO, 2004, p. 67).

Não basta dizer que todos, sem qualquer exceção, têm o mesmo direito de ir à escola; é necessário também que tenham a mesma possibilidade. 0 acesso à educação obrigatória mais cedo se constitui em um instrumento de luta política, para que todas as crianças, inclusive as das classes populares, possam usufruir da igualdade de oportunidades.

Segundo documento do MEC (2006), a entrada antecipada da criança no Ensino Fundamental objetiva garantir à criança um período maior de convivência escolar, ampliando suas oportunidades de aprendizagem. A experiência de professores que atuam ou atuaram nas primeiras séries da escola obrigatória e pesquisas educacionais, desenvolvidas desde a década de 1970, tem mostrado que as crianças que iniciam a escolarização mais cedo são melhor sucedidas no processo de aprendizagem da leitura e da escrita e nos conceitos básicos de Matemática, Ciências e Estudos Sociais. De acordo com Batista (2006), “(...) se as crianças são matriculadas mais cedo, a escola pode dispor de condições mais adequadas para alfabetizá-las, incluindo aquelas pertencentes a meios populares e pouco escolarizados" (p. 2). Dizendo de um outro modo, a inserção da criança das classes populares mais cedo na escola obrigatória permite à mesma uma familiarização mais precoce com um universo cultural mais amplo, 0 que possibilita melhores condições para o seu aprendizado, especialmente, da leitura e da escrita.

Atualmente, em todas as sociedades, há um entendimento, extremamente positivo, de que o direito à educação escolar, mais do que uma exigência da sociedade contemporânea, configurase como um direito que permite o pleno exercício da cidadania. Sabemos que a educação como direito social e político é pressuposto básico para 0 exercício de todos os outros direitos. Daí a intenção de todas as sociedades buscarem garantir aos seus cidadãos o acesso à educação básica (CURY, 2002).

Bobbio (1992) ressalta que, no meio social contemporâneo, não há textos legais que não indiquem o direito à educação como necessário à própria construção do Estado de Direito. Assim, no Estado Moderno, gradativamente 0 direito à educação escolar foi ganhando espaço e sendo reconhecido e garantido o seu acesso aos cidadãos por meio de documentos legais, muitos dos quais de caráter internacional, assinados por países da Organização das Nações Unidas, como a Declaração Universal dos Direitos Humanos de $1948{ }^{1}$. Verificase que desde a Declaração dos Direitos Humanos de 1948, é dito que todo cidadão tem direito à educação e que esta visa o pleno desenvolvimento do ser humano.

0 direito à educação constitui-se como um instrumento para que os indivíduos possam usufruir da igualdade de oportunidades. Esse direito, instituído em lei, torna dever do Estado garantir o acesso de todos por meio da gratuidade. A declaração do direito é um fato significativo, mas mais significativa ainda é a sua garantia por parte do Estado, assegurando-o e implementando-o. Como afirma Jamil Cury:

A declaração e a garantia de um direito
tornam-se imprescindíveis no caso de países,
como o Brasil, com forte tradição elitista e
que tradicionalmente reservam apenas às
camadas privilegiadas este bem social. Por
isso, declarar e assegurar é mais que uma
proclamação solene. Declarar é retirar do
esquecimento e proclamar aos que não

\footnotetext{
${ }^{1}$ No Artigo XXVI - "Todo homem tem direito à instrução. A instrução será garantida, pelo menos nos graus elementares e fundamentais. A instrução elementar será gratuita. (...) DALLARI, 1998, p. 77
} 
sabem, ou esqueceram, que eles continuam a ser portadores de um direito importante. Disso resulta a necessária cobrança deste direito quando ele não é respeitado (2002, p. 259)

A inclusão das crianças de seis anos na escolaridade obrigatória resgata um direito de cidadania, uma vez que permite a uma parcela maior da população se beneficiar de um direito que antes era de poucos. 0 autor supracitado, no mesmo artigo, explica que há uma ligação implícita entre 0 direito à educação escolar e a democracia. A legislação é o suporte que invocará o Estado como provedor desse direito para garantir a igualdade de oportunidade e intervir nas situações de desigualdade. Para o autor, indicado acima "a intervenção tornar-se-á mais concreta quando da associação entre gratuidade e obrigatoriedade, já que obrigatoriedade é um modo de sobrepor uma função social relevante e imprescindível de uma democracia a um direito civil (...)" (2002, p. 249).

Nesse sentido, quando o Estado garante que todas as crianças terão direito ao Ensino Fundamental a partir dos seis anos, este tem em mente, sem sombra de dúvida, as exigências e a natureza da cidadania. Cabe destacar que o Estado está assumindo um compromisso com os cidadãos em formação. Segundo Marshall (1967), o direito da criança de freqüentar a escola está relacionado com o direito do cidadão adulto de ter sido educado.

Temos clareza de que a inclusão de crianças mais novas na escola obrigatória exige tratamento político, administrativo e pedagógico. No aspecto político, aumenta o número de crianças incluídas no Sistema Educacional. Dessa forma, beneficia principalmente as crianças oriundas das classes populares, uma vez que as crianças desta faixa etária, pertencentes às classes mais privilegiadas, já se encontram, majoritariamente, incorporadas ao sistema de ensino nas classes de pré-escola ou na primeira série do Ensino Fundamental, em escolas privadas.

No aspecto administrativo, exige das secretarias de educação investimentos na formação de professores, tanto a formação básica quanto a continuada; na organização da escola em ciclos de aprendizagem; na organização, ampliação e adequação dos espaços físicos, materiais e pedagógicos. Exige, ainda, investir na melhoria das condições de trabalho dos professores, revendo carga horária, número de alunos por classe, sua formação permanente, entre outras tantas questões.

$E$, no aspecto pedagógico, exige das escolas, sobretudo, a reorganização de projetos pedagógicos que assegurem o pleno desenvolvimento dessas crianças em seus aspectos físico, psicológico, intelectual, social e cognitivo, tendo em vista alcançar os objetivos do Ensino Fundamental, sem restringir 0 trabalho pedagógico apenas à preocupação de alfabetizar a criança.

\section{Antecedentes legais da ampliação do Ensino Fundamental}

Desde meados de noventa já era permitida a inclusão de crianças de seis anos completos no Ensino Fundamental. A Lei 9394/96 (Lei de Diretrizes e Bases da Educação Nacional) já afirmava em seu Art. 87, § 3o - I: “Cada Município e, supletivamente, o Estado e a União, deverá: 1 matricular todos os educandos a partir dos sete anos de idade e, facultativamente, a partir dos seis, no Ensino Fundamental". Isto valia já para o Ensino Fundamental de 8 (oito) anos.

Baseando-se neste dispositivo legal é que toda criança com sete anos completos ou a completar, até o final do ano em curso, poderia ser matriculada na primeira série do Ensino Fundamental de oito anos. Para justificar a matrícula dessas crianças, apoiava-se no Art. 29 da LDB que traz em seu conteúdo a seguinte orientação: "A educação Infantil, primeira etapa da educação básica, tem por finalidade o desenvolvimento integral da criança_até seis anos de idade, em seus aspectos físico, psicológico, intelectual e social, complementando a ação da família e da comunidade (grifo nosso).

Com o respaldo legal de que a Educação Infantil era até seis anos, por pressão dos pais de escolas particulares, o Conselho Estadual de Educação do Paraná regulamentou a matrícula na primeira série de crianças que tivessem seis anos completos até 1 o de março. A Deliberação no. 09/01 autorizava a matrícula na 1a . Série, do Ensino Fundamental de 8 (oito) anos, às crianças de sete anos completos ou que completassem seis até 10 de março do ano em curso. O Art. 70 orientava: "Para matrícula de ingresso na primeira série do Ensino Fundamental (oito anos) o candidato deverá ter 7 (sete) anos de idade ou, facultativamente, seis anos completos até o dia 01 de março do ano letivo em que cursará a série" (Deliberação n 09/2001).

Outro ponto que merece ser destacado é que a antecipação do acesso e da obrigatoriedade de escolarização da criança de seis (seis) anos é uma medida contextualizada nas políticas educacionais de todos os países europeus e da maioria dos países da América Latina e do Caribe. Conforme dados da UNESCO (2007), dentre os 41 países da América Latina e do Caribe, em 22 países o início da escolaridade obrigatória é aos seis anos, em 156 é aos 5 (cinco) anos e apenas em quatro países Brasil, El Salvador, Guatemala e Nicarágua - o ingresso era aos 7 (sete) anos, no momento da 
coleta de dados. Dentre aqueles países que iniciam a educação obrigatória aos 6 anos, cinco países consideram o último ano da pré-escola como obrigatório.

Esses dados reforçam o argumento de que, do ponto de vista de uma política educacional afirmativa, também denominada inclusiva, essa medida legal de ampliar para nove anos o Ensino Fundamental, deve ser considerada como um avanço no contexto da realidade brasileira, uma vez que democratiza o acesso, dando oportunidades a todos independente da classe social a que pertença.

Essa medida tomada há vários anos, na maioria dos países, já vinha sido adotada em muitos municípios brasileiros, com a incorporação da última classe da Educação Infantil, denominada pré-escola, no Ensino Fundamental, ampliando dessa forma, os anos iniciais do Ensino Fundamental de quatro para cinco anos.

O PNE - Lei no. 10.172, de 9 de janeiro de 2001 quando trata dos objetivos e metas para o Ensino Fundamental define como metas a serem alcançadas pelos Municípios, Estados e Distrito Federal:

1- Universalizar o atendimento de toda a clientela do Ensino Fundamental, no prazo de cinco anos, a partir da data de aprovação deste plano, garantindo o acesso e a permanência de todas as crianças na escola, estabelecendo em regiões em que se demonstrarem necessários programas específicos, com a colaboração da União, dos Estados e dos Municípios.

2- Ampliar para nove anos a duração do Ensino Fundamental obrigatório com início aos seis anos de idade, à medida que for sendo universalizado o atendimento de 7 a 14 anos.

Portanto, a ampliação do Ensino Fundamental, com a inclusão das crianças de seis anos, é uma política educacional que estava presente, segundo documentos do MEC, em mais de 1.200 municípios brasileiros

No Brasil, hoje, temos importantes documentos legais que sustentam a reorganização das escolas, incluindo as crianças de seis anos completos ou a completar no sistema de escolaridade obrigatória. Todos esses documentos são conquistas resultadas de ações de movimentos sociais e de políticas públicas para diminuir as desigualdades sociais. É de fundamental importância entender que as desigualdades sociais não são naturais, são criadas pelo homem, numa relação de força e dominação (COMPARATO, 2004).

Sendo assim, além do PNE, há outros instrumentos legais que sustentam a organização da escola, ampliando o Ensino Fundamental para nove anos, que se inicia aos seis anos e tem a sua terminalidade aos quatorze anos. No entanto, não basta apenas proclamar esse direito, é necessário dar oportunidade às crianças de desfrutá-lo efetivamente (BOBBIO, 1992).

As balizas legais para a organização dos Sistemas, depois do PNE, foram inscritas a partir do Projeto de Lei no144/2005 aprovado pelo Senado em 25 de janeiro de 2006, que estabelecia a duração mínima de 9 (nove) anos para o Ensino Fundamental, com matrícula obrigatória a partir dos 6 (seis) anos de idade. Medida essa a ser implantada até 2010 pelos Municípios, Estados e Distrito Federal.

Decorrente do PL no. 144/2005, foram instituídas as seguintes medidas legislativas:

A Lei 11.114 de maio de 2005 que altera os Art. 6/30/32 e 87 da LDB/96, instituindo a obrigatoriedade escolar para as crianças de seis anos, sem alterar a duração do Ensino Fundamental.

A Resolução no. 03/2005 do Conselho Nacional de Educação - Câmara de Educação Básica - define normas nacionais para a ampliação do Ensino Fundamental. Em seu Art.1ำ, trata da antecipação e obrigatoriedade da matrícula no Ensino Fundamental das crianças de seis anos, e no seu Art. 20 orienta a organização do Ensino Fundamental de nove anos e a Educação Infantil, adotando os seguintes critérios: a Educação Infantil, primeira etapa da Educação Básica, atende crianças até cinco anos de idade, e o Ensino Fundamental atende as crianças de seis até quatorze anos de idade. 0 Ensino Fundamental tem duas etapas: A primeira etapa, denominada anos iniciais, com cinco anos de duração, atende crianças de seis até dez anos. A segunda etapa, anos finais do Ensino Fundamental, com quatro anos de duração, atende as crianças de onze a quatorze anos.

A Lei №. 11.274, de 06 de fevereiro de 2006, que altera a redação dos Art. 29, 30,32 e 87 da Lei no 9.394, de 20 de dezembro de 1996, que estabelece as diretrizes e bases da educação nacional, dispondo sobre a duração de 9 (nove) anos para o Ensino Fundamental, com matrícula obrigatória a partir dos 6 (seis) anos de idade.

A Emenda Constitucional no 053 de 20 de dezembro de 2006 que dá nova redação aos Art. 70 $, 23,30,206,208,211$ e 212 da Constituição Federal e ao artigo 60 do Ato das Disposições Constitucionais Transitórias.

Não se pode ignorar que, pela Constituição Brasileira e a LDB/96, o Ensino Fundamental é direito público subjetivo. É o mesmo que dizer que o Ensino Fundamental é um direito fundamental, 
sendo necessário reconhecê-lo, protegê-lo, promovê-lo e assegurá-lo. 0 vocábulo assegurar significa dar a certeza do acesso ao ensino. Assim, o Ensino Fundamental, no sistema de educação brasileiro, é prioridade, e como tal, deve ser assegurado. Os demais níveis de ensino serão priorizados a partir deste.

Neste sentido, o cumprimento deste DIREITO não é somente de interesse do indivíduo, mas, sobretudo, da coletividade. E, ainda, o cidadão, sozinho ou associado a outras pessoas, tem poderes legais para obrigar o poder público a garanti-lo e assegurá-lo. Assegurar representa dar a certeza do acesso ao ensino, em qualquer circunstância, para todas as crianças a partir de seis anos. Isso exige das esferas públicas, pela desigualdade social mantida no País, maiores recursos financeiros para dar condições de igualdade pedagógica e social, que assegurem às crianças das classes populares a mesma oportunidade que têm as crianças das classes sociais economicamente mais privilegiadas.

Nosso posicionamento é que se a Constituição Federal, hoje, prescreve que a Educação Infantil atende as crianças até 5 (cinco) anos, toda criança com seis anos completos ou a completar, no ano em curso, tem o direito assegurado de estar matriculada na escola obrigatória, que no Brasil, denomina-se Ensino Fundamental.

Outro fato que não deve passar desapercebido é o de que a inscrição de um direito no código legal de um País, como o nosso, não acontece da noite para o dia. A declaração de um direito é um fato significativo, mas mais significativa, ainda, é a sua garantia por parte do Estado.

A ampliação da escolaridade obrigatória é uma conquista para as classes populares e, a nosso ver, precisa ser defendida e deve ser estendida cada vez mais, agora incluindo as crianças de seis anos; daqui a pouco, precisaremos lutar para estendê-la às crianças de faixas etárias mais novas, tornando obrigatória a Educação Básica e construindo, aos poucos, uma Escola para a Infância, que, no dizer de Sônia Kramer, estudiosa de políticas públicas para a infância, visa propiciar às nossas crianças 0 conviver com afetos, brincadeiras, saberes, valores enfim, garantir um espaço onde a seriedade e o riso estejam presentes. Isto vale tanto para as crianças que estão na Educação Infantil como para aquelas que estão no Ensino Fundamental. Segundo a estudiosa:

Na educação infantil e no ensino fundamental, o objetivo é atuar com liberdade para assegurar a apropriação e a construção do conhecimento por todos. Na educação infantil, o objetivo é garantir o acesso, de todos que assim o desejarem, a vagas em creches e préescolas, assegurando o direito das crianças de brincar, criar, aprender. Nos dois temos grandes desafios: o de pensar a creche, a pré-escola e a escola como instâncias de formação cultural; o de ver as crianças como sujeitos de cultura e história, sujeitos sociais" (KRAMER, 2006, p. 20).

Outras medidas de cunho pedagógico, administrativo e financeiro deverão acompanhar esta política, pois não se trata de transferir para as crianças de seis anos os conteúdos e atividades da tradicional primeira série, mas de desenvolver uma proposta pedagógica considerando a singularidade das crianças dessa faixa etária.

É importante entender que a inclusão das crianças de seis anos no Ensino Fundamental é um direito social dos mais contundentes para a cidadania dos brasileiros. Ele precisa ser assegurado e o trabalho pedagógico desenvolvido deve levar em conta a singularidade das ações infantis.

Necessário se faz garantir às crianças dessa faixa etária 0 atendimento nas suas necessidades (a de aprender e a de brincar). Isto não vale apenas para as crianças de seis anos, mas de todas as crianças de seis até 10 anos, faixa etária dos anos iniciais do Ensino Fundamental (KRAMER, op. cit).

Para finalizar, entendemos que a inclusão, simplesmente, da criança de seis anos no Ensino Fundamental, não garante a melhoria da qualidade do ensino, mas todos sabemos que a criança que, desde muito cedo, tem contato com o mundo da leitura e da escrita e outros bens culturais, é melhor sucedida no seu processo de escolarização.

\section{Referências}

1. BATISTA, A.A.G. Ensino fundamental de 9 anos: um importante passo à frente. Boletim UFMG, Belo Horizonte, v. 32, n.1522, março de 2006.

2. BOBBIO, N. A Era dos Direitos. Rio de Janeiro: Campus, 1992.

3. CARVALhO, J. S. (org). Educação, Cidadania e Direitos Humanos. São Paulo: Vozes, 2004.

4. BRASIL. Ministério da Educação. Ensino Fundamental de nove anos: Orientações gerais. 2004.

5. COMPARATO, F. K. O princípio da igualdade e a escola. In: CARVALHO, J.S. (Org.). Educação, Cidadania e Direitos Humanos. São Paulo: Vozes, 2004, p. 67 - 84. 
6. CURY, C. R. J. A Educação Básica no Brasil. Educação e Sociedade, Campinas, v. 23, n. 80, p. 169-201, set-dez., 2002.

7. DALLARI, D. de A. Um breve histórico dos direitos humanos. In: CARVALHO, José Sérgio (org). Educação, Cidadania e Direitos Humanos. Petrópolis: Vozes, 2004. p. 19-42.

8. KRAMER, S. A infância e sua singularidade. In: BRASIL. Ensino Fundamental de Nove Anos Orientações para a inclusão da criança de seis anos de idade. Brasília: Ministério da Educação, 2006. p. 17- 30.

9. MARSHAL, T. Cidadania, classe social e status. Rio de Janeiro: Zahar, 1967.

10. OREALC/UNESCO: Situación Educativa de América Latina y el Caribe: garantizando la educación de calidade para todos, 2007.

11. PARANÁ. Conselho Estadual de Educação. Deliberação no. 09 de 1o de outubro de 2001. Matrícula de ingresso, por transferência e em regime de progressão parcial; o aproveitamento de estudos; a classificação e a reclassificação; as adaptações; a revalidação de vida escolar em estabelecimentos que ofertam Ensino Fundamental e Médio nas suas diferentes modalidades. Disponível em: http://www.pr.gov.br/cee (Acesso em 09/10/2007)

12. Conselho Estadual de Educação. Delïberação no. 2 de 13 de abril de 2007. Alteração do artigo 12 da Deliberação №. 03/06CEE. Disponível em: http://www.pr.gov.br/cee (Acesso em 09/10/2007).

Recebido em 24/09/2007

Reformulado em 22/04/2008

Aceito em 30/04/2008 